\title{
Low Leukocyte MGMT Accompanies Temozolomide-Induced Myelotoxicity in Brain Tumor Patients
}

\author{
Julia E. Stokes\#, Michael S. Bobola\#, Marc C. Chamberlain ${ }^{\#, *}$ and John R. Silber ${ }^{\#}$ \\ Departments of Neurological Surgery (JES, MSB, MCC, JRS), and Neurology (MCC), University of \\ Washington, USA
}

\begin{abstract}
Objective: The methylating agent temozolomide (TMZ) has markedly improved clinical outcome for patients with glioblastoma and other gliomas. While TMZ has comparatively low systemic toxicity, a minority of patients experience severe myelotoxicity that compromises TMZ treatment, necessitating dose reductions and treatment delays. These limitations emphasize the need to develop markers to identify individuals susceptible to TMZ-induced myelosuppression. The purpose of this small pilot study is to examine the association between treatment-limiting myelosuppression in primary brain tumor patients receiving TMZ and expression of $O^{6}$-methylguanine-DNA methyltransferase (MGMT) in peripheral blood leukocytes (PBL). MGMT is the sole human activity that removes TMZinduced, cytotoxic $\mathrm{O}^{6}$-methylguanine adducts from DNA.
\end{abstract}

Methods: MGMT biochemical activity and MGMT promoter methylation status, a surrogate measure of MGMT expression, were assayed in $\mathrm{PBL}$ from 10 patients who experienced treatment-limiting myelotoxicity during TMZ therapy, 8 patients who experienced no myelotoxicity during TMZ treatment, and 10 disease-free, untreated controls.

Results: MGMT activity was detectable in all 28 PBL samples, and all displayed an unmethylated promoter indicative of MGMT expression. Mean PBL MGMT activity was 2-fold lower in patients who experienced myelotoxicity compared to patients without myelotoxicity $\left(8.9 \pm 3.9 \mathrm{vs} .18 \pm 8.1 \mathrm{fmol} / 10^{6} \mathrm{cells} ; P \leq 0.015\right)$ and to untreated controls $(8.9 \pm 3.9 \mathrm{vs} .16$ $\pm 6.8 \mathrm{fmol} / 10^{6}$ cells; $\left.P \leq 0.015\right)$.

Conclusions: These preliminary data indicate that low MGMT activity in PBL is associated with myelotoxicity in primary brain tumor patients receiving TMZ, and may have value if confirmed in a larger study as a marker to identify patients at greater risk of treatment-limiting myelosuppression.

Keywords: Primary brain tumor, temozolomide (TMZ), glioblastoma, myelosuppression, thrombocytopenia, O6methylguanine-DNA methyltransferase, promoter methylation, MGMT enzymatic activity, peripheral blood leukocytes, biomarkers.

\section{INTRODUCTION}

Inclusion of temozolomide (TMZ) in post-surgical therapy has produced clinically relevant improvement in survival for patients with glioblastoma [1]. In part this benefit derives from the low cumulative toxicity associated with TMZ, as contrasted with other alkylating chemotherapies. However, a small fraction of patients (approximately 7\%) develop severe myelosuppression (defined as clinically relevant $\geq$ grade III cytopenias), which limits or halts treatment $[2,3]$. Even when $T M Z$ is discontinued, persistence of cytopenia can delay initiation of alternative cytotoxic therapies compromising further treatment. Such adverse consequences highlight the need for a clinically tractable biomarker of susceptibility to TMZinduced myelotoxicity.

\footnotetext{
*Address corresponding to this author at the Division of Neuro-Oncology, 825 Eastlake Ave E, PO Box 19023, MS G-4940, Seattle, WA 98109-1023, USA; Tel: 206-288-8280; Fax: 206-288-2000; E-mail: chambemc@uw.edu

\#Julia E. Stokes, data acquisition, data analysis, manuscript preparation.

"Michael S. Bobola, data acquisition, data analysis.

"Marc C. Chamberlain, study design, manuscript preparation, data interpretation.

\#John R. Silber, study design, funding, manuscript preparation, study supervision.
}

The search for molecular markers of myelosensitivity has focused primarily on the repair protein $0^{6}$-methylguanine-DNA methyltransferase (MGMT), the sole human activity that removes TMZinduced cytotoxic $0^{6}$-methylguanine adducts from DNA [4]. A role for MGMT in myelosensitivity to TMZ is suggested by reports that activity in peripheral blood mononuclear cells varies widely in normal individuals [5], and that low levels of MGMT in peripheral blood mononuclear cells more frequently accompanied higher-grade leukopenia and thrombocytopenia in melanoma patients treated with TMZ or its analog dacarbazine [6]. In this preliminary work, we assayed MGMT activity in peripheral blood leukocytes (PBL) from primary brain tumor patients treated with TMZ. We found that significantly lower MGMT activity accompanies treatment-limiting myelosuppression in TMZ-treated patients. Our results indicate that TMZinduced myelotoxicity in primary brain tumor patients reflects, at least in part, a reduced capacity to remove $\mathrm{O}^{6}$-methylguanine adducts from DNA, and suggest that PBL MGMT activity may serve as a marker for TMZ myelosensitivity in this patient population. 


\section{MATERIALS AND METHODS}

\section{Patient Population and Leukocyte Isolation}

Blood was obtained, with informed consent, from 18 patients with a diagnosis of primary brain tumor who had been treated with TMZ at the University of Washington Medical Center, and from 10 disease-free controls. Thirty $\mathrm{mL}$ of blood was collected in 1:1000 sodium heparin and held for no longer than one hour at room temperature prior to isolation of PBL by gradient centrifugation using Histopaque (Sigma). Washed cell pellets were flash-frozen and stored as duplicate aliquots at $-70{ }^{\circ} \mathrm{C}$. The average interval between the last day of TMZ ingestion and blood draw was $305 \pm$ 339 days (range, 27-849 days) for patients experiencing myelotoxicity and $164 \pm 184$ days (range, 21-528 days) for patients experiencing no myelotoxicity.

\section{Extract Preparation and DNA Isolation}

Whole cell extracts were prepared from one PBL aliquot by lysis on ice for 40 minutes in $25 \mathrm{mM}$ Tris- $\mathrm{HCl}$ (pH 8.0), 5 mM EDTA, $150 \mathrm{mM} \mathrm{NaCl}, 10 \%$ glycerol and $0.1 \%$ Nonidet $\mathrm{P} 40$, followed by centrifugation at 10,000 $\mathrm{x} \mathrm{g}$ for $30 \mathrm{~min}$ to pellet insoluble debris. DNA was isolated from a second PBL aliquot by solubilization in sodium dodecylsulfate followed by serial salt and alcohol precipitation using commercially available reagents (PureGene, Gentra Systems).

\section{MGMT Assay and CpG Methylation Status}

MGMT activity (fmol $\mathrm{O}^{6}-\left[{ }^{3} \mathrm{H}\right]$ methylguanine transferred $/ 10^{6}$ cells) was measured by standard biochemical assay that quantifies transfer of $\left[{ }^{3} \mathrm{H}\right]$ methyl groups from $\mathrm{O}^{6}-\left[{ }^{3} \mathrm{H}\right]$ methylguanine in DNA to protein [7]. The methylation status of 9 informative $\mathrm{CpG}$ residues in the MGMT promoter was determined by

Table 1: PBL MGMT, Treatment and Myelotoxicity

\begin{tabular}{|c|c|c|c|c|}
\hline Age/Sex & $\mathrm{Dx}^{1}$ & MGMT $^{2}$ & TMZ therapy ${ }^{3}$ & Toxicity $^{4}$ \\
\hline \multicolumn{5}{|c|}{ Patients with myelosuppression } \\
\hline $39 / \mathrm{M}$ & $\mathrm{AOA}$ & $3.6 \pm 0.5$ & $\mathrm{RT}+\mathrm{TMZ} ; \mathrm{TMZ} \times 1$ & thrombocytopenia; TMZ discontinued during $\mathrm{RT}$; reduced dose \& delays \\
\hline $54 / F$ & GBM & $4.1 \pm 1.6$ & $\mathrm{RT}+\mathrm{TMZ} ; \mathrm{TMZ} \times 2$ & thrombocytopenia; reduced dose \& delays \\
\hline $59 / F$ & GBM & $7.5 \pm 2.6$ & $R T+T M Z ; T M Z \times 5$ & thrombocytopenia; TMZ discontinued during $\mathrm{RT}$; reduced dose \& delays \\
\hline $44 / F$ & $\mathrm{AO}$ & $7.9 \pm 4.6$ & $\mathrm{RT}+\mathrm{TMZ} ; \mathrm{TMZ} \times 5$ & pancytopenia; reduced dose \& delays \\
\hline $60 / F$ & GBM & $7.9 \pm 1.6$ & $\mathrm{RT}+\mathrm{TMZ} ; \mathrm{TMZ} \times 5$ & neutropenia; TMZ discontinued during RT; reduced dose \& delays \\
\hline $59 / \mathrm{M}$ & GBM & $8.0 \pm 2.3$ & $\mathrm{RT}+\mathrm{TMZ} ; \mathrm{TMZ} \times 3$ & thrombocytopenia; reduced dose \& delays \\
\hline $64 / F$ & AA & $8.7 \pm 1.8$ & $\mathrm{RT}+\mathrm{TMZ} ; \mathrm{TMZ} \times 4$ & thrombocytopenia; reduced dose \& delays \\
\hline $49 / F$ & $\mathrm{O}$ & $12 \pm 1.3$ & $\mathrm{TMZ} \times 18$ & neutropenia; reduced dose \& delay \\
\hline $28 / F$ & GBM & $15 \pm 3.8$ & $\mathrm{RT}+\mathrm{TMZ} ; \mathrm{TMZ} \times 7$ & thrombocytopenia; reduced dose \& delays \\
\hline $28 / F$ & AA & $15 \pm 4.8$ & $\mathrm{RT}+\mathrm{TMZ} ; \mathrm{TMZ} \times 6$ & thrombocytopenia; reduced dose \& delays \\
\hline \multicolumn{5}{|c|}{ Patients with no myelosuppression } \\
\hline $47 / F$ & GBM & $7.8 \pm 3.5$ & TMZ $\times 4$ & None; continued treatment \\
\hline $34 / \mathrm{M}$ & $\mathrm{AOA}$ & $11 \pm 1.9$ & $\mathrm{RT}+\mathrm{TMZ} ; \mathrm{TMZ} \times 24$ & None; completed treatment \\
\hline $32 / \mathrm{M}$ & PNET & $13 \pm 4.2$ & TMZ $\times 4$ & None; continued treatment \\
\hline $66 / M$ & GBM & $14 \pm 2.7$ & $\mathrm{RT}+\mathrm{TMZ} ; \mathrm{TMZ} \times 5$ & None; refused cycle 6 \\
\hline $40 / M$ & AA & $16 \pm 4.9$ & $\mathrm{TMZ} \times 14$ & None; continued treatment \\
\hline $48 / \mathrm{M}$ & $\mathrm{AO}$ & $22 \pm 3.5$ & $\mathrm{RT}+\mathrm{TMZ} ; \mathrm{TMZ} \times 10$ & None; continued treatment \\
\hline $64 / M$ & GBM & $24 \pm 4.1$ & $\mathrm{RT}+\mathrm{TMZ} ; \mathrm{TMZ} \times 8$ & None; completed treatment \\
\hline $65 / M$ & 0 & $33 \pm 5.4$ & TMZ $\times 24$ & None; completed treatment \\
\hline
\end{tabular}

${ }^{1}$ Diagnosis: AA, anaplastic astrocytoma; AO, anaplastic oligodendroglioma; AOA, mixed anaplastic oligodendroglioma-astrocytoma; GBM, glioblastoma; O, oligodendroglioma; PNET, primitive neuroectodermal tumor.

${ }^{2}$ Mean \pm SD of MGMT activity (fmol $\mathrm{O}^{6}-\left[{ }^{3} \mathrm{H}\right]$ methylguanine $/ 10^{6}$ cells) is the average of 2 or more amounts of extract in at least 2 separate assays.

${ }^{3} \mathrm{RT}+\mathrm{TMZ}$ : TMZ at $75 \mathrm{mg} / \mathrm{m}^{2}$ was given daily during radiotherapy (RT) and was continued after radiation at $200 \mathrm{mg} / \mathrm{m}^{2}$ for 5 consecutive days every 28 days for the number of cycles indicated. Five tumors received $\mathrm{TMZ}$ following recurrence after prior adjuvant radiotherapy. 
methylation-specific PCR [8]. Bisulfite deamination, PCR primers and reaction conditions were as described by Hegi et al. [9]. Methylation status was determined by at least two separate bisulfite reactions and a minimum of two amplification reactions for each aliquot of bisulfite-treated DNA. DNA from the MGMTdeficient human glioma line SNB19 and the MGMTproficient line SF767 served as controls for methylated and unmethylated promoters, respectively.

\section{RESULTS}

\section{Tumor Characteristics and Treatment}

As shown in Table 1, tumors from patients treated with TMZ included 8 WHO grade IV glioblastomas (GBM), 7 WHO grade III anaplastic gliomas, 2 grade II oligodendrogliomas and one supratentorial primitive neuroectodermal tumor (PNET). Thirteen tumors received concurrent $T M Z$ and radiotherapy followed by adjuvant TMZ while the remaining 5 were treated with single agent TMZ. Of the tumors, 10 were from patients that experienced grade III or greater myelosuppression necessitating dose reductions or treatment delays (Table 1). The remaining 8 patients experienced no treatment-limiting count suppression during therapy. The two tumor populations did not differ in age (48 \pm 13 vs. $50 \pm 14$ years), although the preponderance $(8 / 10)$ of patients experiencing myelotoxicity were female in accord with earlier findings [2].

Blood was also obtained from disease-free volunteers (4 females and 6 males), ranging in age from 24 to 62 years old (mean $\pm S D=50 \pm 14$ ), to serve as untreated controls.

\section{MGMT Activity and Promoter Methylation}

All PBL samples from tumor patients and diseasefree controls had detectable MGMT activity, ranging from 3.6 to $33 \mathrm{fmol} / 10^{6}$ cells (Figure 1 and Table 1 ). In addition, all samples displayed only unmethylated MGMT promoters (Figure 2) in accord with previous reports [10]. Activity did not differ between patients who experienced no treatment-limiting myelosuppression and control subjects $\left(18 \pm 8.1 \mathrm{vs} .16 \pm 6.8 \mathrm{fmol} / 10^{6}\right.$ cells; $P \leq 0.30$ ), suggesting that prior exposure to $T M Z$ had no lasting effect on MGMT expression. However, as shown in Figure 1, MGMT activity was significantly lower in PBL from patients who experienced treatmentlimiting myelotoxicity compared to patients without myelosuppression $\left(8.9 \pm 3.9\right.$ vs. $18 \pm 8.1 \mathrm{fmol} / 10^{6}$ cells; $P \leq 0.015)$ and compared to untreated controls (8.9 \pm 3.9 vs. $16 \pm 6.8 \mathrm{fmol} / 10^{6}$ cells; $\left.P \leq 0.015\right)$. These data indicate that low MGMT activity is associated with TMZ-induced myelotoxicity and suggest that failure to remove cytotoxic $0^{6}$-methylguanine may increase bone marrow susceptibility to TMZ cytotoxicity.

\section{DISCUSSION}

Little is known about the molecular mechanisms responsible for TMZ-induced myelosuppression in primary brain tumor patients. In this initial pilot study, we determined that MGMT activity in PBL is significantly lower in patients who experienced

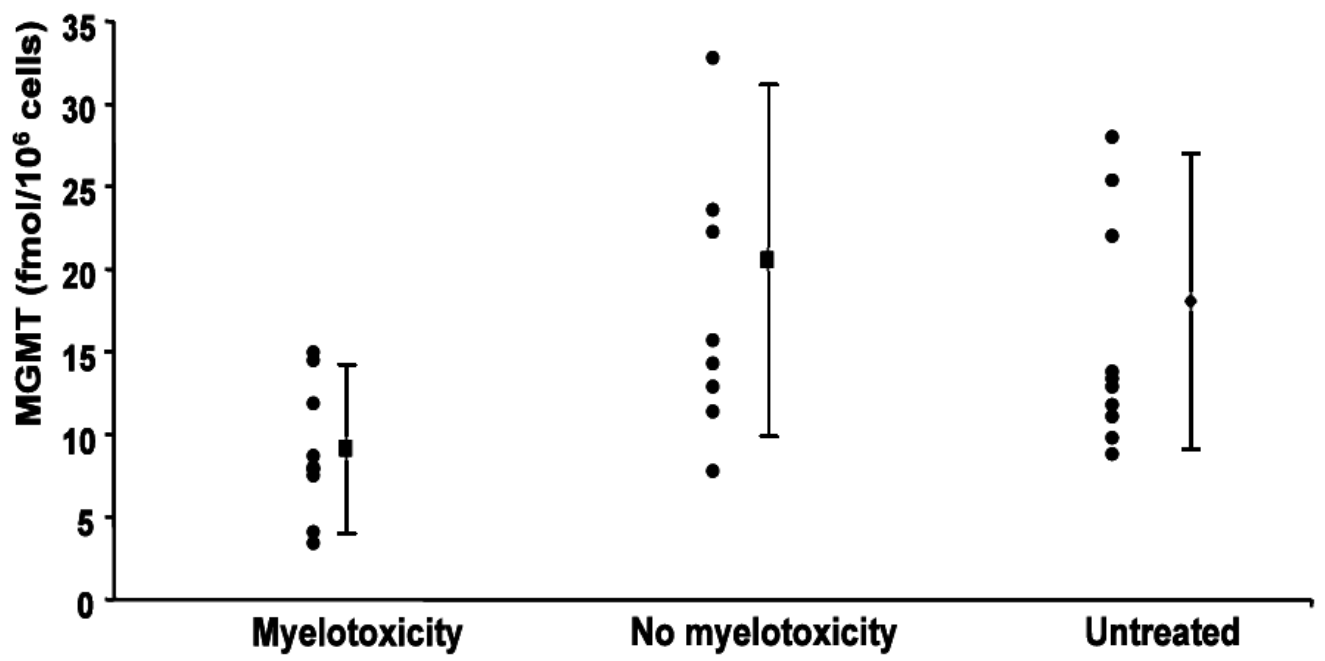

Figure 1: MGMT activity in PBL of TMZ-treated and untreated subjects. Distribution of MGMT activity determined by standard biochemical assay (7) in PBL from TMZ-treated primary brain tumor patients who suffered treatment-limiting myelotoxicity, primary brain tumor patients who experienced no myelotoxicity, and untreated, disease-free volunteers. The mean \pm SD of MGMT activity (fmol $0^{6}-\left[{ }^{3} \mathrm{H}\right]$ methylguanine $/ 10^{6}$ cells) is shown for each group. The activities of three tumors in the first group were essentially identical (Table 1) and appear as a single point in the figure. 


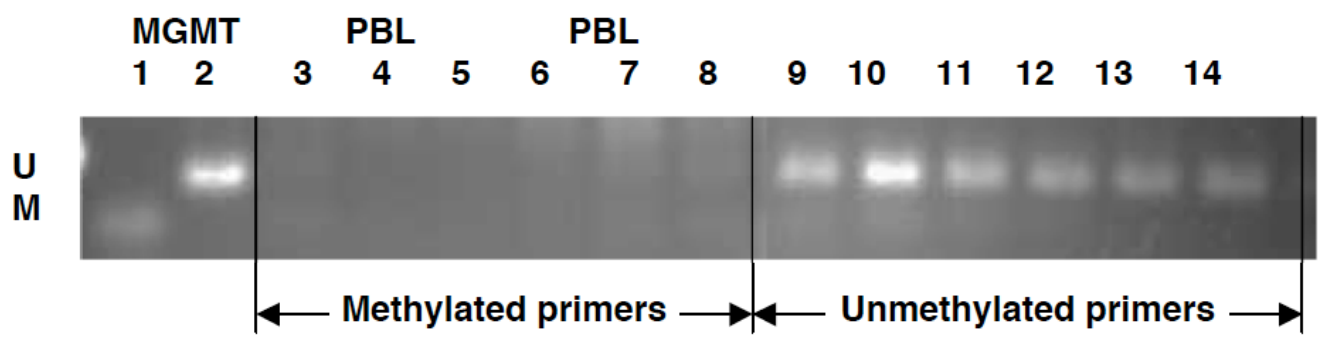

Figure 2: MGMT promoter methylation status in PBL. Determination of methylation status for 6 representative PBL samples by methylation specific PCR, as described in Materials and Methods, is shown. PCR product was detected only in reactions specific for unmethylated MGMT promoter, indicative of MGMT expression, in the genomic DNA of all PBL samples from TMZtreated patients and untreated volunteers. The two lanes at the left show the positions of methylated and unmethylated PCR products from SNB19, an MGMT-non-expressing human glioma cell line and SF767, an MGMT-expressing human glioma cell line, respectively; lanes 3-8 show the absence of bands for 5 PBL DNA samples amplified with primers specific for methylated MGMT; lanes 9-14 show bands for the same PBL DNA samples amplified with primers specific for unmethylated MGMT. U, position of unmethylated PCR product; M, position of methylated PCR product.

myelosupression, indicating that TMZ-induced $\mathrm{O}^{6}$-meG contributes to myelotoxicity. Our results also suggest that PBL MGMT activity can be used to estimate risk for myelosuppression. Ideally, high-risk patients could be offered TMZ dose reductions or alternative therapies to avoid the development of treatment-related myelotoxicity. Low risk patients could be offered TMZ with little hazard of toxicity, or even dose intensification. However, the overlap of MGMT activities between myelosuppressed and unsuppressed patients (Figure 1 and Table 1) suggests that additional resistance mechanisms contribute to TMZ sensitivity and limit the ability of MGMT alone to predict myelotoxicity. TMZ produces a dozen base adducts, including a number with documented cytotoxicity [4], suggesting that deficits in repair of one or more lesions other than $0^{6}$ meG might contribute to toxicity. Also, mechanisms that negate the cytotoxicity of unrepaired $\mathrm{O}^{6}$-meG, such as homologous recombination and replicative bypass [4]' may greatly reduce TMZ cytotoxicity in cells with relatively low MGMT. Further study is required to resolve these possibilities.

Methylation of $\mathrm{CpG}$ islands in the MGMT promoter, a presumptive marker of suppressed gene expression, has been associated with decreased MGMT content in brain tumor cells [4]. We therefore hypothesized that methylation-specific PCR analysis of PBL DNA would show a correlation between $\mathrm{CpG}$ methylation and low MGMT activity. However, we found no association between methylation status and MGMT activity; all specimens displayed only an unmethylated signal. This finding suggests at first glance that promoter methylation status, a clinically tractable assay, has no utility as a marker for risk of TMZ-induced myelotoxicity. Conceivably, MGMT expression in PBL is associated with a different pattern of promoter $\mathrm{CpG}$ island methylation than that observed in glial tumors.
Alternatively, MGMT expression in PBL may be mediated by other mechanisms, as evidenced by a recent study that identified MGMT polymorphisms associated with TMZ-induced myelotoxicity [10]. Though these study results are provocative, the small sample size limits generalizing these findings to all patients with gliomas treated with $\mathrm{TMZ}$ and suggests confirmation of the study findings is required before this assay is used as a predictive biomarker for $T M Z$ induced myelosuppression.

\section{DISCLOSURE}

Research support provided in part by $\mathrm{NIH}$ grant number CA104593 (JR Silber), the Department of Neurological Surgery, University of Washington and a gift to the Brain Tumor Research Fund in memory of Ro Jean Mount. The funding sources did not influence the content of this manuscript.

\section{CONFLICT OF INTEREST}

All authors report no conflict of interest.

\section{ACKNOWLEDGEMENTS}

Supported in part by NIH grant number CA104593 (JR Silber), the Department of Neurological Surgery, University of Washington and a gift to the Brain Tumor Research Fund in memory of Ro Jean Mount. The funding sources did not influence the content of this manuscript. We thank Dr. A. Blank for critical review of the manuscript.

\section{REFERENCES}

[1] Chamberlain MC. Evolving strategies: Future treatment of glioblastoma. Expert Rev of Neurotherapeutics 2011; 11(4): 519-32.

http://dx.doi.org/10.1586/ern.11.30 
[2] Armstrong TS, Cao Y, Scheurer ME, et al. Risk analysis of severe myelotoxicity with temozolomide: the effects of clinical and genetic factors. Neuro Oncol 2009; 11: 825-32. http://dx.doi.org/10.1215/15228517-2008-120

[3] Villano JL, Letarte N, Yu JM, Abdur S, Bressler LR. Hematologic adverse events associated with temozolomide. Cancer Chemother Pharmacol 2012; 69(1): 107-113. 2011 May 26. [Epub]

[4] Christmann M, Verbeek B, Roos WP, Kaina B. O(6)Methylguanine-DNA methyltransferase (MGMT) in normal tissues and tumors: Enzyme activity, promoter methylation and immunohistochemistry. Biochim Biophys Acta 2011; 1816: 179-90.

[5] Jansen M, Bardenheuer W, Sorg UR, Seeber S, Flasshove $\mathrm{M}$, Moritz T. Protection of hematopoietic cells from $\mathrm{O}^{6}$ alkylation damage by $\mathrm{O}^{6}$-methylguanine DNA methyltransferase gene transfer: studies with different $O^{6}$ alkylating agents and retroviral backbones. Eur $\mathrm{J}$ Haematol 2001; 67: 2-13. http://dx.doi.org/10.1034/j.1600-0609.2001.067001002.x

[6] Sabharwal A, Waters R, Danson S, et al. Predicting the myelotoxicity of chemotherapy: the use of pretreatment $O^{6}$ methylguanine-DNA methyltransferase determination in peripheral blood mononuclear cells. Melanoma Res 2011; 21: 502-508.

http://dx.doi.org/10.1097/CMR.0b013e32832ccd58

[7] Silber JR, Blank A, Bobola MS, Ghatan S, Kolstoe DD, Berger MS. $\mathrm{O}^{6}$-methylguanine-DNA methyltransferasedeficient phenotype in human gliomas: frequency and time to tumor progression after alkylating agent-based chemotherapy. Clin Cancer Res 1999; 5: 807-14.

[8] Esteller M, Garcia-Foncillas J, Andion E, et al. Inactivation of the DNA-repair gene MGMT and the clinical response of gliomas to alkylating agents. N Engl J Med 2009; 343: 135054. http://dx.doi.org/10.1056/NEJM200011093431901

[9] Hegi ME, Diserens AC, Gorlia T, et al. MGMT gene silencing and benefit from temozolomide in glioblastoma. N Engl J Med 2005; 352: 997-1003.

http://dx.doi.org/10.1056/NEJMoa043331

[10] Sylvester RK, Steen P, Tate JM, et al. Temozolomideinduced severe myelosuppression: analysis of clinically associated polymorphisms in two patients. Anticancer Drugs 2011; 22: 104-10.

http://dx.doi.org/10.1097/CAD.0b013e3283407e9f

Received on 16-05-2012

Accepted on 20-07-2012

Published on 21-08-2012

DOI: http://dx.doi.org/10.6000/1929-2279.2012.01.01.08

(C) 2012 Stokes et al.; Licensee Lifescience Global.

This is an open access article licensed under the terms of the Creative Commons Attribution Non-Commercial License (http://creativecommons.org/licenses/by-nc/3.0/) which permits unrestricted, non-commercial use, distribution and reproduction in any medium, provided the work is properly cited. 